\title{
Promoting Successful Youth Mentoring Relationships: A Preliminary Screening Questionnaire
}

\author{
Jean Rhodes, ${ }^{1,3}$ Ranjini Reddy, ${ }^{1}$ Jennifer Roffman, ${ }^{1}$ and Jean B. Grossman ${ }^{2}$
}

Youth mentoring programs are an increasingly popular intervention, and although successful mentoring relationships can promote a range of positive developmental outcomes, relationships that fail can lead to decrements in a youth's functioning and self-esteem. The present research develops and validates a youth mentoring relationship quality inventory, based on data from a national evaluation of Big Brothers Big Sisters (BBBS) mentoring programs $(\mathrm{N}=347$ youth). This tool can be administered to adolescents who have been assigned mentors in order to assess the quality of the relationship as it is forming and to identify dyads that may need additional support before those relationships fail. Implications of such a tool for mentoring interventions and research are discussed.

Editors' Strategic Implications: Reliability and validity data are presented for a measure of youth's perceptions of the quality of their mentoring relationship. This measure shows promise as a tool for research and evaluation of a wide array of mentoring programs due to its brevity, demonstrated psychometrics, and straightforward focus on the mentoring relationship.

KEY WORDS: mentoring; youth; questionnaire; self-esteem; relationships.

Supportive older adults — teachers, neighbors, extended family members, or volunteers - can lead to positive outcomes among youth living in high-risk circumstances (Rhodes, 2002). For example, in one recent study, those youth who had natural mentors (i.e., not forged through mentoring programs) were significantly less likely than other youth to take part in a range of problem behaviors (Beier,

\footnotetext{
${ }^{1}$ Department of Psychology, University of Massachusetts, Boston, Massachusetts.

${ }^{2}$ Princeton University.

${ }^{3}$ Address correspondence to Jean Rhodes, Department of Psychology, University of Massachusetts, Boston, 100 Morrissey Blvd., Boston, Massachusetts 02125-3393; e-mail: jean.rhodes@umb.edu.
} 
Rosenfeld, Spitalny, Zanksy, \& Bontempo, 2000). Similarly, in a study of over 700 low-income urban adolescents, Zimmerman, Bigenheimer, and Notaro (2002) found that youth who had natural mentors had more favorable attitudes toward school and were less likely to use alcohol, smoke marijuana, and become delinquent than those without mentors. Unfortunately, many children and adolescents do not readily find supportive non-parent adultsin their communities. Changing family and marital and employment patterns, overcrowded schools, and less cohesive communities have dramatically reduced the presence of caring adults in the lives of youth (Eccles \& Grootman, 2002; Putnam, 2000). The social fabric is stretched particularly thin in urban centers, which are largely bereft of the middleclass adults who once served as respected authority figures in the community (Anderson, 1999).

Mentoring programs are being increasingly advocated as a means of redressing the decreased availability of adult support and guidance in the lives of youth (Grossman \& Tierney, 1998; Rhodes, 2002). Over two and a half million American youth are involved in school- or community-based volunteer mentoring programs each year, and the numbers are rising at an unprecedented rate (Carson, 2002). Although mentoring relationships can last for years and be the source of considerable support, as many as half dissolve within a matter of months (Freedman, 1993; Grossman \& Rhodes, 2002). The detection and management of early difficulties can increase the likelihood that relationships will thrive beyond the initial stages (Morrow \& Styles, 1995). In this study, we sought to empirically derive a set of relationship characteristics that were associated with duration and positive youth outcomes and could serve as a diagnostic tool.

\section{BACKGROUND}

A growing number of evaluations suggest that volunteer mentoring relationships can positively influence a range of outcomes, including improved peer and parental relationships, academic achievement, self-concept, and behavior (Aseltine, Dupre, \& Lamlein, 2000; DuBois, Holloway, Valentine, \& Cooper, 2002; Grossman \& Tierney, 1998). Like other relationships, however, youth mentoring relationships can vary in closeness and duration, in ways that have implications for their effectiveness. Whereas some mentoring relationships can be extraordinarily influential, others are only marginally helpful or even dissatisfying and hurtful. Grossman and Rhodes (2002) recently explored this variation with particular attention to the duration of mentoring relationships. Youth who were in relationships that lasted a year or longer reported improvements in academic, psychosocial, and behavioral outcomes, while progressively fewer positive effects emerged among youth who were in relationships that terminated after six months or a year, or between three and six months. Adolescents who were in dyads that terminated within a very short period of time reported decrements in several indicators of functioning relative to control youth. Along similar lines, Slicker and Palmer (1993) found that students who were "effectively mentored" (as measured 
by the quality and length of the relationship) had better academic outcomes than controls, whereas those whose relationships terminated prematurely experienced a significant decline in self-concept when compared with youth who were not mentored at all.

Researchers have begun to uncover common elements of mentoring programs that are associated with longer duration and success. For example, in a review of the literature on mentoring, Sipe (1998) identified three major elements of successful programs: screening, orientation and training, and support and supervision. Similarly, DuBois et al. (2002) used meta-analysis to review 55 evaluations of mentoring programs. Stronger effects emerged for those youth in programs employing practices similar to those identified by Sipe. These "best practices" were associated with youth reporting more frequent contact with their mentors, feeling some emotional closeness to the mentors, and participating in the mentoring relationship for a longer period of time.

The efforts of program staff, mentors, and youth to facilitate the formation of strong, long-lasting mentoring bonds appear to be crucial to the achievement of positive youth outcomes through mentoring. This suggests that the process through which mentoring and other relationship-based interventions are effective hinges on the strength of this interpersonal bond. Several researchers have noted the power of a close, trusting intergenerational connection. After examining over 600 mentorprotégé pairs, Herrera and her colleagues observed: "At the crux of the mentoring relationship is the bond that forms between the youth and mentor. If a bond does not form, then youth and mentors may disengage from the match before the mentoring relationship lasts long enough to have a positive impact on youth" (Herrera, Sipe, McLanahan, Arbreton, \& Pepper, 2000, p. 28). The quality of the bond that is formed between a young person and a caring adult (such as in a mentor-youth dyad) is thus the core element in of relationship-based youth interventions (Rhodes, 2002). Only after a strong emotional connection has been established through consistent meetings, can the two participants proceed to achieving the objectives of the program in which they are involved, such as improving academic competence, increasing self-esteem, or enhancing interpersonal relationships. Taken together, these findings underscore the importance of maintaining adequate levels of support and supervision in mentoring programs to ensure relationship closeness, longevity, and effectiveness. If detected early, problems that might potentially undermine relationships can be resolved. Therefore, caseworkers and supervisors need to be on the lookout for early signs of trouble.

Although youth are likely to anticipate generally caring relationships, they might be particularly sensitive to any difficulties or slights that emerge in the early, vulnerable stages of the relationship. The negative aspects of relationships may outweigh, or even cancel out, the positive aspects. After studying thousands of marital relationships, Gottman (1995) concluded that, in stable relationships, positive interactions occur about five times more frequently than negative interactions. Particularly since the negative interactions are so much more salient than the positive, this ratio has implications for the health of relationships. Rook (1999) 
conducted a study in which participants were asked to complete a form at the end of each day that assessed their mood and any positive or negative social interactions that they had experienced. Negative exchanges occurred less often than positive exchanges, but were related more consistently to daily mood. As Rook explains, "When family or friends fail to provide support, or when they're critical, demanding, or insensitive, the effects can be devastating. It may take as many as five positive social exchanges to balance one negative exchange" (p. 1).

The effects of negative exchanges may be particularly salient during the adolescent years, when issues of acceptance and rejection are paramount. Feelings of belonging are central to adolescents' sense of self, which is often defined through others' eyes (Noam, 1997). Although this dependence on others' impressions can be beneficial when mentoring relationships are enduring and supportive, adolescents are apt to feel more profound disappointment if their mentor does or says anything that is hurtful. In addition, adolescents may be more likely than children or adults to hold negative expectations for their interactions with adults, as they strive to establish their independence from parental authority (Baumrind, 1987; Furstenberg, 1990). In particular, youth who are involved with mentoring programs may have experienced disappointment in past relationships with adults (Grossman \& Rhodes, 2002).

Despite the best of intentions, however, mentoring program staff are often burdened with relatively large numbers of relationships to monitor, and can easily miss the subtle warning signs that a relationship is in trouble. In studies examining program practices across a wide range of mentoring programs, Sipe and Roder (1999) found that the median ratio of mentors to paid staff was 20:1 and that only one-third of these programs contacted mentors more than once a month. Similarly, Herrera et al. (2000) found that $20 \%$ of volunteers "almost never" talk to staff people in the programs they work with, and $9 \%$ have no contact with staff at all. Such observations highlight the need for more intensive monitoring of relationships, and the potential utility of an instrument that could efficiently screen troubled dyads, so as to best allocate limited staff resources.

In the current study, we sought to develop and validate a diagnostic tool for predicting the longevity and effectiveness of mentoring relationships. Within this context, we explored the construct of relationship quality, and the processes by which different aspects of this connection translated into more and less successful mentoring relationships.

\section{METHOD}

\section{Participants}

The sample for the current study was drawn from Public/Private Ventures' national evaluation of Big Brothers Big Sisters (BBBS; Grossman \& Tierney, 1998). Most agencies give preference to youth who have no more than one parent 
actively engaged in their lives. Other criteria include age (5 through 18$)$, residence in the catchment area, and an agreement by the parent and child to follow agency rules. Applicants to BBBS were randomly assigned to either a treatment or control group and administered a set of standardized questionnaires at baseline and 18 months later over the telephone by a trained interviewer. The interviewers worked for a national survey firm, Abt Associates, which was subcontracted by the program evaluators (Public/Private Ventures). Of the 1,138 youth who applied to Big Brother Big Sister programs during the study period, $85 \%$ completed both baseline and follow-up ( $N=959 ; 487$ treatments and 472 controls) telephone interviews. At the conclusion of the study, 378 (approximately 78\%) of the treatment youth had been matched. The current sample consisted of 347 of these youth who were assigned to mentors. The 31 youth who were rematched after early termination were excluded from the analyses. Sixty percent of the matches were still active, while $40 \%$ were no longer meeting. After 18 months, the ongoing matches had been meeting for an average of 12.9 months, while the closed matches met for an average of 9 months. Over $70 \%$ of the youth met with their mentors at least three times a month, and approximately $47 \%$ of the matches met one or more times per week. An average meeting lasted 3.8 hours. At the end of the 18-month follow-up, $54.4 \%$ of the matches had met for more than 12 months.

Over half of the analysis sample were boys (59.4\%) and members of minority groups $(55.3 \%)$. Thirty-eight percent of the minority youth were African Americans, $8.6 \%$ were Hispanic, and the remaining were members of a variety of other racial/ethnic groups. Participants ranged in age from 9.4 to 15.9 $(M=12.10)$, most $(69 \%)$ between the ages of 11 and 13 . The majority of the youth lived with their mothers $(87.6 \%) ; 2.3 \%$ lived with a grandparent; and the remaining participants lived with fathers, in extended families, or in non-family arrangements. Approximately $41 \%$ of the youth lived in households that were receiving either food stamps and/or public assistance, and most were from urban neighborhoods $(73.2 \%)$.

\section{Measures}

\section{Youth-Mentor Relationship Questionnaire}

This questionnaire is based on previous qualitative work on youth mentoring (Morrow \& Styles, 1995). It adapts items from The Relatedness Questionnaire (Lynch \& Wellborn, 1987), which contains two subscales, emotional quality and psychological proximity seeking. The Youth-Mentor Relationship Questionnaire consists of a set of 74 survey items expected to predict relationship quality. The questions, which were administered only at post-test, tap into both positive $(N=$ 51) (e.g., my mentor sees my side of things; I look forward to seeing my mentor) and negative $(N=23)$ (e.g., my mentor gives advice that doesn't work; my mentor makes fun of me in ways I don't like) experiences and impressions. The questions 
vary from typical kinds of activities and conversation topics engaged in by the pair to the perceived reliability and trustworthiness of the mentor. Youth were also questioned about whether the Big Brother or Big Sister actively helped to make them feel better when they were unhappy, how they felt when they spent time with their mentor, their general impressions of the mentor and the relationship, and whether they wished they had a different mentor. Each item was scored on a Likert scale (1-4), indexing either frequency with which the event in the statement took place ("hardly ever" to "pretty often") or how true the statement was of the relationship with the mentor ("not at all like that" to "really like that"). Items were reverse scored so that higher scores reflected more positive relationship patterns.

\section{Self-Perception Profile for Children}

The global self-worth, scholastic competence, and behavioral conduct subscales (six items each) of the Self-Perception Profile for Children (Harter, 1986) were used to index youth's perceptions of their academic abilities, their behavior, and their sense of personal identity and self-worth. Items on each of the subscales are written in a format that requires the respondent to first indicate with which of two descriptions of groups of adolescents they identify more closely, and then to describe how accurately they feel these descriptions relate to their own experiences. For example, a sample general self-worth item reads: "Some kids are pretty pleased with themselves BUT other kids are often unhappy with themselves." Respondents must first select either the former or the latter group as more accurately describing how they feel about themselves, and then rate the accuracy of this description. Each item was scored on a 4-point scale where 4 represents the most positive sense of self-worth, behavior, or academic competence. No difficulties were reported in its administration, the scale has been successfully administered via telephone in other studies with young adolescents, and this test has shown strong validity and reliability in previous studies (e.g., Harter, 1986; Schumann et al., 1999). Reliability for the scales at pre- and post-test were as follows: general self-worth: pre $=.71$; post $=.75$; scholastic competence: pre $=.68$; post $=.77$; behavioral conduct: pre $=.72$; post $=.76$.

\section{School Value}

The 18-item Berndt and Miller (1986) school value scale was used to index how involved youth felt about different aspects of their schools. Items cover several different aspects of the school experience and its importance to the adolescent. Each item was rated on a 4-point scale ( $1=$ "hardly ever"; $4=$ "pretty often"). The items were summed and higher values reflect a higher level of school value. The scale has shown excellent validity and reliability (Berndt \& Miller, 1986; 
Grossman \& Tierney, 1998), and reliability at pre- and post-test in this sample were as follows: pre $=.73$; post $=.79$.

\section{Grades}

A single item was used to index self-reported grades. Youth were asked to select which category best described their grades on an 8-point scale: 1 (D's and F's), 2 (D's), 3 (C's and D's), 4 (C's), 5 (B's and C's), 6 (B's), 7 (A's and B's), and 8 (A's).

\section{Demographic Characteristics}

Single items were used to assess students' gender (female coded 1) and age. In addition, details on the duration of match, match frequency, and length of contact per visit were obtained from the case managers' reports of the youth-mentor matches.

\section{Design and Procedure}

From the network of more than 500 BBBS local agencies, eight were selected to participate in the outcome study. The key selection criteria for inclusion in the impact study were a large, active caseload; a waiting list; and geographic diversity. With only a few exceptions, all of the youth who enrolled in the eight selected BBBS agencies during the intake period were encouraged to participate in the research. Once a youth was informed about the study, determined to be eligible, and assented to participate (along with a parent's signed, informed consent), he or she was randomly assigned to either the treatment or control group. Only $2.7 \%$ of the youth refused to participate in the evaluation. The control group was placed on a waiting list for a post-study match. All participants were interviewed by telephone before they knew their experimental status. Follow-up interviews were conducted 18 months later by telephone. In addition to the questions administered at baseline, the follow-up surveys included items dealing with the match, such as the duration of the match, several aspects of relationship quality between mentor and protégé, and reasons for terminating the relationship.

Agency staff matched adult volunteers with youth on the basis of gender (only same-sex dyads) and a variety of other factors, including shared interests, reasonable geographic proximity, and same-race match preference. The majority of volunteers were White $(75.4 \%)$. Almost all worked full-time $(98.1 \%)$ with the majority in managerial, professional, technical, sales, administrative support, or service areas. Sixty-one percent were single. Six had themselves been involved in the BBBS program as adolescents. All volunteers underwent an intensive screening 
process, followed by agency-based training and ongoing case management. The training covered agency policies, communication, and relationship building as well as issues that might be of particular relevance to participating youth (e.g., grieving, sexual abuse). Dyads typically engaged in a wide variety of leisure- and career-oriented discussions and activities with the general goal of promoting the youth's positive development.

\section{RESULTS}

A two-step procedure was employed in arriving at the mentoring relationship scale. The first step was to explore the underlying structure of items indexing mentor-youth relationships. To this end, exploratory factor analysis (EFA) was conducted $^{4}$ and primarily served the purpose of reducing the item set for the second step, confirmatory factor analysis (CFA). Following this, regression and mediation models were used to assess any relationships between the mentoring relationship scales and outcome variables.

\section{Factor Analysis}

From the original set of 74 items, those that were ambiguous and/or displayed a considerable degree of overlap with other items were first excluded. This resulted in 61 items that were subject to the EFA. All items were scored such that higher scores on an item reflected higher positive levels of the attributes measured by the items. To maintain consistency with the maximum likelihood approach to parameter estimation employed in the ensuing CFA, the maximum likelihood method for factor extraction was employed. An oblique rotation was specified, as moderate correlation was expected between the factors (specifically, the oblimin method with Kaiser normalization was used with delta set to zero). Decisions regarding the number of factors to extract relied on conceptual and empirical considerations. The empirical decision rule included the scree test, the eigenvalue criterion, and the total variance accounted for by each factor (Cattell, 1966; Hair, Anderson, Tatham, \& Black, 1998).

Although 15 factors were extracted, the first four accounted for $34 \%$ of the final variance and were taken to represent items that most reliably captured relationship quality. ${ }^{5}$ Furthermore, there was a substantial drop in eigenvalue and

\footnotetext{
${ }^{4}$ A previous EFA was conducted on these items by Jean Grossman (Grossman \& Johnson, 1999). The purpose of that study was to develop in-program indicators of success that were correlated with longer-term outcomes. Twelve relationship factors based on youth responses were extracted. The three that had the greatest power to predict outcome impacts-an emotional engagement scale, a youth-centeredness scale, and a youth disappointment scale-were retained for the study.

${ }^{5}$ Listwise deletion was utilized and resulted in a sample size of 298 for this set of analysis. This sample size increased to 332 for the CFA analysis.
} 
amount of variance between the 4th and 5th factors, indicating that more trivial factors followed. Items loaded above .40 for each factor, and, with the exception of two items, all items loaded on single factors. The first factor, "Not dissatisfied," accounted for $11 \%$ of the total variance and consisted of three items reflecting the youth's global sense of dissatisfaction with their mentors. The second factor, "Helped to cope," accounted for $12 \%$ of the variance and consisted of three items reflecting how well the mentor helped the youth deal with problems. The third factor, "Not unhappy," accounted for $6.73 \%$ of the variance and consisted of six items reflecting the absence of specific negative emotions, such as feeling mad, ignored, betrayed, bored, and disappointed when the youth was with the mentor. The last factor, "Trust not broken," accounted for 3.59\% of the variance and consisted of six items reflecting relationship patterns and the mentor's reliability and trustworthiness. Internal consistency of the factors was good, ranging from .62 to .83 . The specific items included in each factor can be found in Table I.

\section{Confirmatory Factor Analyses}

Confirmatory factor analysis (CFA) was used to confirm the structure of the four factors obtained in EFA. All models were estimated via LISREL 8.30 (Jöreskog \& Sörbom, 2000). Parameter estimates were based on maximumlikelihood procedures. A total of 15 items from the EFA entered the model testing procedures of CFA. Skewness coefficients ranged from -2.43 to .55 , none indicating significant deviations from symmetry. The CFA model was specified so that the items were hypothesized onto four factors reflecting the pattern obtained by the EFA. Furthermore, no cross loadings of the items on the factors were allowed. The factors were also allowed to correlate freely. As recommended (cf. Bollen, 1989; Kline, 1998), a number of Goodness-of-Fit indexes were used to evaluate model fit. These included the chi-square/ $d f$ index (given the reliance of the chi-square on sample size; absolute values $\leq 2.5$ ), Root mean square error of approximation (RMSEA < .05) with the $90 \%$ confidence interval, and the Comparative Fit Index $(>.90)$.

The original model fit the data poorly $\left(\chi^{2} / d f=3.72\right.$, RMSEA $=.09,90 \%$ $\mathrm{CI}=.08-.10 ; \mathrm{CFI}=.89$ ), indicating some degree of misfit. The parameter estimates as well as standardized residuals and modification indexes were thus examined. Although all parameter estimates loaded significantly on the defined latent factors, large modification indexes revealed specific areas of model misfit. However, any model respecification must be based on theoretical considerations and not solely on the absolute values of these modification indexes. In the current study, model respecifications were based on theoretical interpretability of the latent factors. Thus, based on information from the modification indexes as well as relevant social support and mentoring research (Noam, 1997; Rhodes, 2002; Rook, 1999), three items were allowed to cross-load on the latent factors (see 
Table I. Items and Reliability of the Mentoring Scales

\begin{tabular}{|c|c|c|c|}
\hline Subscale & Reliability & Items & Item anchor \\
\hline Not dissatisfied & .74 & $\begin{array}{l}\text { Sometimes my mentor } \\
\text { promises/promised that we will } \\
\text { do something and then we don't } \\
\text { do it } \\
\text { My mentor makes fun of me in } \\
\text { ways I don't like } \\
\text { I wish my mentor was different }\end{array}$ & $\begin{array}{l}\text { 1-4: very true-not at } \\
\text { all true }\end{array}$ \\
\hline Helped to cope & .81 & $\begin{array}{l}\text { When something is bugging me, } \\
\text { my mentor listens while I get it } \\
\text { off my chest } \\
\text { My mentor has lots of good ideas } \\
\text { about how to solve a problem } \\
\text { My mentor helps me take my } \\
\text { mind off things by doing } \\
\text { something with me }\end{array}$ & $\begin{array}{l}\text { 1-4: hardly } \\
\text { ever-pretty often }\end{array}$ \\
\hline Not unhappy & .85 & $\begin{array}{l}\text { When my mentor gives me advice, } \\
\text { s/he makes me feel kind of } \\
\text { stupid } \\
\text { When I am with my mentor, I feel } \\
\text { ignored } \\
\text { When I am with my mentor, I feel } \\
\text { bored } \\
\text { When I am with my mentor, I feel } \\
\text { mad } \\
\text { I feel that I can't trust my mentor } \\
\text { with secrets because s/he would } \\
\text { tell my parent/guardian } \\
\text { When I am with my mentor, I feel } \\
\text { disappointed }\end{array}$ & $\begin{array}{l}\text { 1-4: very true-not at } \\
\text { all true }\end{array}$ \\
\hline Trust not broken & .81 & $\begin{array}{l}\text { When my mentor gives me advice, } \\
\text { s/he makes me feel kind of } \\
\text { stupid } \\
\text { I wish my mentor knew me better } \\
\text { I wish my mentor spent more time } \\
\text { with me } \\
\text { I wish my mentor asked me more } \\
\text { what I think } \\
\text { I feel that I can't trust my mentor } \\
\text { with secrets because s/he would } \\
\text { tell my parent/guardian } \\
\text { Sometimes my mentor promises } \\
\text { that we will do something and } \\
\text { then we don't do it }\end{array}$ & $\begin{array}{l}\text { 1-4: very true-not at } \\
\text { all true }\end{array}$ \\
\hline
\end{tabular}

Table I). The final model fit the data well $\left(\chi^{2} / d f=2.43\right.$, RMSEA $=.06,90 \%$ $\mathrm{CI}=.05-.08 ; \mathrm{CFI}=.94){ }^{6}$ The majority of the parameter estimates in the model

\footnotetext{
${ }^{6}$ Note that although only the final model is reported, model testing progressed with each path successively estimated. The nested chi-square tests revealed the successive models to fit the data better. For the final model, modification indexes suggested adding paths from items " making fun of" and "bored" to the latent variable "Helped to cope." These changes were not included as they were not theoretically meaningful.
} 
Table II. Correlations of the Mentoring Scales and Youth and Match Characteristics

\begin{tabular}{lcccc}
\hline & $\begin{array}{c}\text { Trust not } \\
\text { broken }\end{array}$ & $\begin{array}{c}\text { Not } \\
\text { dissatisfied }\end{array}$ & $\begin{array}{c}\text { Helped } \\
\text { to cope }\end{array}$ & $\begin{array}{c}\text { Not } \\
\text { unhappy }\end{array}$ \\
\hline Youth Age & -.01 & -.03 & -.01 & -.03 \\
Youth gender (female) & .04 & -.02 & .08 & .02 \\
Length of match & $.25^{* *}$ & $.21^{* *}$ & $.18^{* *}$ & $.21^{* *}$ \\
Frequency of match & -.07 & -.08 & -.10 & -.05 \\
Duration per visit & .04 & .11 & $.13^{*}$ & .02 \\
\hline
\end{tabular}

Note. $N=311$ (listwise).

${ }^{*} p<.05 .{ }^{* *} p<.01$.

were large (.50) and significant. Based on modification indices, three items in this model were permitted to cross-load. The item "mentor doesn't keep promises" was allowed to load on "Not dissatisfied" and "Trust not broken," and the items "mentor can't be trusted to keep secrets from the parent/guardian" and "mentor makes protégé feel stupid when giving advice" were allowed to load on "Not unhappy" and "Trust not broken." Factors were moderately interrelated, with correlations ranging from .30 to .77 . The largest correlation was between "Not dissatisfied" and "Not unhappy" $(r=.77)$. Despite this strong association, the two factors are conceptually distinct. The items in the former factor address protégés' overall impressions of their mentors, and the latter factor addresses the emotional impact that the mentor is having on the protégé.

\section{The Mentoring Scales}

Four factors, encompassing 15 items from the survey, stood out as ways to distinguish between successful and unsuccessful relationships. The final breakdown of items in each of the scales, with internal consistency, is presented in Table I. Cronbach's internal consistency of the scales was good, ranging from .74 for "Not dissatisfied" to .85 for "Not unhappy."

Correlations among the scales and demographic characteristics of the youth and match characteristics are presented in Table II. Neither age nor gender of the youth showed a consistent relationship with the scales. In fact, the correlations suggested that age and gender had little relationship to mentoring patterns. Small but significant positive correlations were obtained among the scales and length of match. The highest correlation was between "Trust not broken" and length of match $(r=.25)$, indicating that adolescents in longer matches also tended to report higher levels of trustworthiness or reliability from their mentor. Surprisingly, there was no relationship between frequency of contact with mentor and any of the scales, although youth who met with their mentors for a longer time during each visit tended to also report higher levels of "Helped to cope," $(r=.13)$. 
To examine whether gender and age played a role in mentoring quality, a $2 \times 2$ MANOVA was conducted with the four mentoring scales as the dependent variables. The median split was utilized to form age groups. Neither gender nor age differences were obtained for any of the four scales (Wilks lambda $=.99$, $p>.10)$. A separate MANOVA was conducted to explore differences in mentoring quality by youth minority status. ${ }^{7}$ Although the overall Wilks lambda suggested differences (Wilks lambda $=.97, p<.05$ ), the follow-up univariate tests revealed no differences in the mentoring scales for white versus minority youth. As a result, for all ensuing analyses, the data were collapsed over these demographic categories.

A one-way MANOVA was also performed to examine any differences between youth matched for varying duration and mentoring quality as defined by the four scales. For this analysis, duration of match was categorized into three time periods, 1-6 months, 7-12 months, and 13-19 months. A highly significant Wilks lambda (lambda $=.92, p<.001$ ) suggested overall differences in the scales across the three time periods. Follow-up univariate analysis revealed a significant main effect for duration of match for "Trust not broken" $(F(2,329)=8.00$, $p<.000)$, "Not dissatisfied" $(F(2,329)=5.24, p<.000)$, "Helped to cope" $(F(2,329)=8.63, p<.000)$, and "Not unhappy" $(F(2,329)=5.29, p<.01)$. Using Tukey HSD and an alpha error rate of .05, the post-hoc analyses revealed the following pattern: Youth involved in the longest matches (13-19 months) reported significantly more positive levels on each of the four scales, indicating greater satisfaction and fewer negative feelings. In particular, they reported levels of feeling good when with the mentor ("Not unhappy"; $M=21.45$ ), liking the mentor ("Not dissatisfied"; $M=10.60$ ), aid from the mentor ("Helped to cope"; $M=10.17$ ), and mentor reliability ("Trust not broken"; $M=19.63$ ) that were significantly higher than those reported by youth matched for one to six months ("Not unhappy" $M=19.92$; "Not dissatisfied" $M=9.68$; "Helped to cope" $M=8.51$; "Trust not broken" $M=17.17)$. In addition, youth matched for 7-12 months also reported higher levels of aid from the mentor $(M=9.64)$ than those matched for a shorter period of time $(M=8.51)$. On the other hand, youth matched for one to six months $(M=19.92)$ and from seven to twelve months $(M=20.25)$ were also statistically more likely to evidence higher levels of negative emotion towards their mentors than youth matched longer than 13 months $(M=21.45)$. There were no other consistent significant differences between the groups. Although this analysis does not reveal developmental patterns, it suggests that youth in longer matches are also those who are able to form more satisfying and more intimate relationships with their mentors.

\footnotetext{
${ }^{7}$ Youth minority status was not included in the gender by age MANOVA as this resulted in a very unbalanced design. As this set of analyses explored group differences, a separate analysis on minority status was conducted.
} 


\section{Predictive Influences of the Mentoring Scales}

Hierarchical multiple regression analyses were employed to examine the relative, independent contributions of the four relationship quality scales on academic outcomes (scholastic competence, school value, self-reported grades) and psychological adjustment (general self-esteem, behavioral conduct). In each regression equation, youth age and gender were first entered (step 1$),{ }^{8}$ followed by the length of match (step 2), and finally by the four mentoring subscales (step 3). We further examined whether the mentoring scales mediated the relationship between length of the match and outcomes following the criteria laid out by Baron and Kenny (1986).

\section{Predicting Academic Outcomes Over Time}

Table III presents the hierarchical regression results for the academic indicators at post-test. Overall, the models accounted for $28 \%$ of the variance in the youths' scholastic competence, $27 \%$ of the variance in their school value, and $15 \%$ in self-reported grades. As can be seen in the table, "Trust not broken" predicted scholastic competence above and beyond the demographic characteristics or the length of match. The more the youth felt that their mentors had not let them down or broken their trust, the more their scholastic competence increased over time. "Not unhappy," on the other hand, predicted school value after controlling for youth characteristics and prior levels of school value. The stronger the perception that the mentor did not make the youth unhappy, the more the youth valued school over time. With respect to grades, none of the mentoring scales significantly predicted self-reported grades at post-test.

\section{Predicting Psychological Adjustment Over Time}

Table IV presents the results of the effects of youth-mentor relationships on general self-esteem and behavioral conduct over time. As can be seen in the table, the models accounted for $30 \%$ of the variance in general self-esteem and about $12 \%$ of the variance in behavioral conduct. Although behavioral conduct is not significantly predicted by any of the mentoring scales, the mentoring scales account for almost one fourth of the explained variance in general self-esteem. Three of the four mentoring scales, namely, "Helped to cope," "Trust not broken," and "Not dissatisfied," differentially predicted general self-esteem above and beyond the

\footnotetext{
${ }^{8}$ For the hierarchical regression analyses, there was some attrition in the sample due to missing data (approximately 11\%). Comparison of the cases dropped versus those retained for analyses revealed only youth age as a significant differentiator. Youth in short vs. longer matches differed with gender, with girls more likely to present in the group matched longer. For these reasons, these two demographic variables were controlled in all the OLS. Note that the sample size for all ensuing analyses was 309.
} 


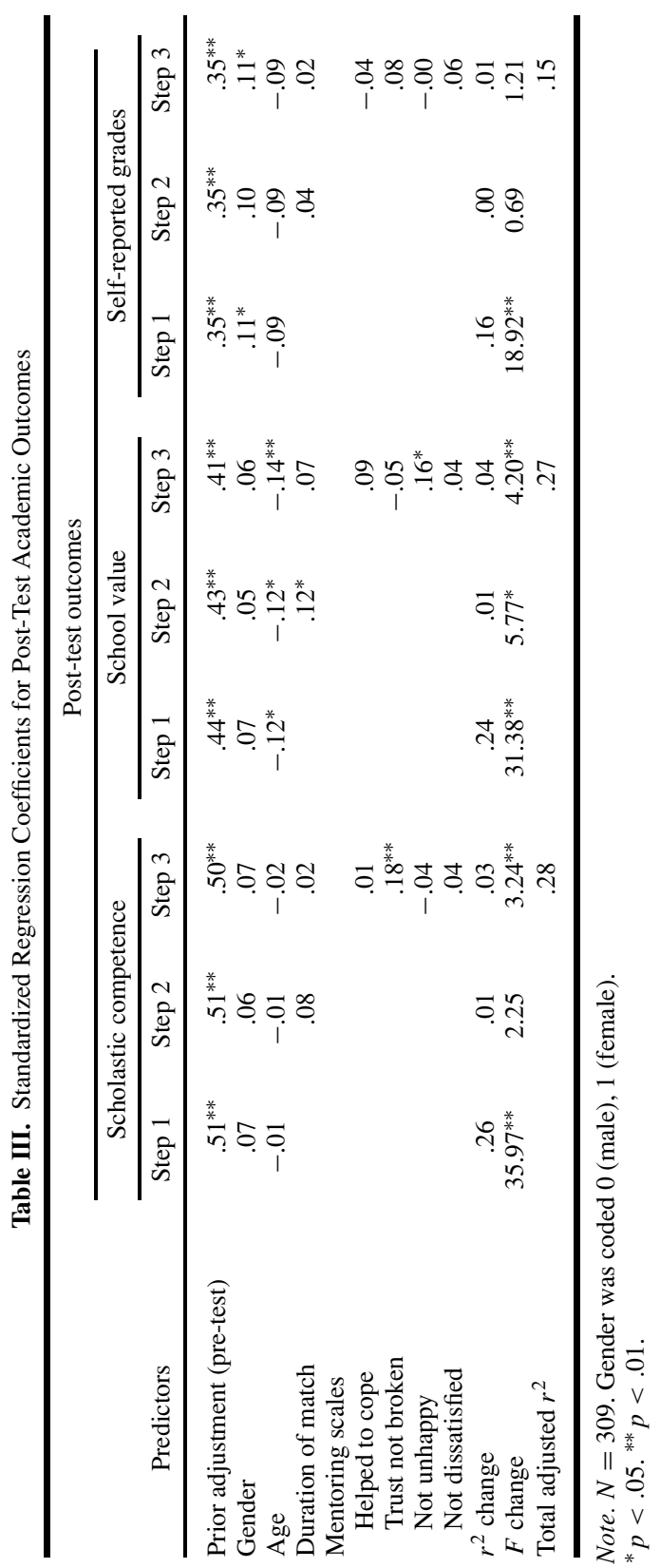


Table IV. Standardized Regression Coefficients for Post-Test Psychological Adjustment

\begin{tabular}{|c|c|c|c|c|c|c|}
\hline \multirow[b]{3}{*}{ Predictors } & \multicolumn{6}{|c|}{ Post-test outcomes } \\
\hline & \multicolumn{3}{|c|}{ General self-esteem } & \multicolumn{3}{|c|}{ Behavioral conduct } \\
\hline & Step 1 & Step 2 & Step 3 & Step 1 & Step 2 & Step 3 \\
\hline $\begin{array}{l}\text { Prior adjustment } \\
\text { (pre-test) }\end{array}$ & $.44^{* *}$ & $.42^{* *}$ & $.39^{* *}$ & $.34^{* *}$ & $.32^{* *}$ & $.32^{* *}$ \\
\hline Gender & $-.17^{* *}$ & $-.19^{* *}$ & $-.17^{* *}$ & .09 & .07 & .07 \\
\hline Age & .01 & .01 & -.00 & -.02 & -.02 & -.03 \\
\hline Duration of match & & $.11^{*}$ & .07 & & $.11^{*}$ & .08 \\
\hline \multicolumn{7}{|l|}{ Mentoring scales } \\
\hline Helped to cope & & & $-.12^{*}$ & & & .00 \\
\hline Trust not broken & & & $.18^{*}$ & & & .11 \\
\hline Not unhappy & & & -.07 & & & -.00 \\
\hline Not dissatisfied & & & $.18^{*}$ & & & -.02 \\
\hline$r^{2}$ change & .23 & .25 & .31 & .12 & .01 & .01 \\
\hline$F$ change & $31.13^{* *}$ & $4.77^{*}$ & $7.12^{* *}$ & $13.62^{* *}$ & $3.71^{*}$ & 0.80 \\
\hline Total adjusted $r^{2}$ & & & .29 & & & \\
\hline
\end{tabular}

Note. $N=309$. Gender was coded 0 (male), 1 (female).

${ }^{*} p<.05{ }^{* *} p<.01$.

effects of prior levels. "Trust not broken" and "Not dissatisfied" both predicted self-esteem in the expected directions, with more positive perceptions of "Trust not broken" and "Not dissatisfied" associated with greater increases in self-esteem at post-test. Surprisingly, "Helped to cope" negatively predicted self-esteem at post-test.

\section{Tests of Mediation}

We further wanted to explore whether the mentoring scales actually mediated the relationship between duration of match and the outcomes specified above. To this end, we examined the mediational effects of each of the mentoring scales following the criteria of Baron and Kenny (1986). As a first step to the test of mediation, each of the outcomes was regressed on duration of match. Length of match was not significantly related to scholastic competence, self-reported grades, self-esteem, or behavioral conduct (as indexed by the non-significant path coefficients). Tests of mediation were therefore not possible. The duration of the relationship, however, significantly predicted school value at the post-test, controlling for prior levels of school value ( $\beta=.13, p=.01)$. Tests of mediation were therefore possible for this outcome. "Trust not broken" marginally mediated the relationship between duration of match and school value, as evidenced by the significant drop in the effects of duration of match on school value (from $\beta=.13$, $p<.01$ to $\beta=.10, p=.05$ ), when "Trust not broken" was introduced into the model. Similar trends were seen for "Helped to cope" and "Not dissatisfied." 
When these mentoring scales were introduced into the model, the significance of duration on match on school value dropped $\beta=.23, p<.01$ to $\beta=.09$, $p=.05$ for "Helped to cope" and $\beta=.22, p<.01$ to $\beta=.09, p=.05$ for "Not dissatisfied." In each instance, the mentoring scale significantly predicted school value ("Helped to cope": $\beta=.13, p=.01$; "Not dissatisfied": $\beta=.13, p=.01$ ). On the other hand, "Not unhappy" completely mediated the effects of duration of match on school value. A previously significant relationship between duration and school value $(\beta=.22, p<.01)$ became nonsignificant when "Not unhappy" was introduced in the model $(\beta=.09, p>.05)$. "Not unhappy" continued to be a significant predictor of school value in this model $(\beta=.17, p<.01)$.

\section{DISCUSSION}

In this study, we developed a measure consisting of four relationship quality scales that can be used to evaluate the strength of mentoring dyads and to isolate appropriate targets for support from program staff. Interestingly, successful mentoring relationships tended to be defined less in terms of positive attributes than by the absence of disappointment and other negative feelings. Although there were many positively worded items (e.g., "when something is bugging me, my mentor has lots of good ideas on how to solve problems"; "my mentor helps me get along better with my teachers") on the original scale, only three of them held predictive power. Specifically, four factors, encompassing 15 of the original 74 items, emerged in the analysis. One factor tapped into the extent to which youth felt that their mentors helped them solve problems, while three of the factors were characterized by the infrequent endorsement of items registering dissatisfaction and feelings of hurt and betrayal in the relationships.

The pattern of results reported in this study underscores the damaging effects of disappointment and mistrust in mentoring relationships, and are consistent with findings in the social support literature, which have suggested that the negative aspects of relationships can outweigh or negate the positive aspects. Many youth in mentoring programs have already experienced disappointment in past relationships with adults (Grossman \& Rhodes, 2002). For them, the infrequent endorsement of negatively worded items can be interpreted as a positive comment on the nature of the relationship, namely, that the mentor did not fulfill the protégé's pessimistic prophesy.

This pattern of findings may also relate, in part, to the data analytic process. Because youth were far more likely to endorse positive statements, there was greater variability on the negative, and thus those items were more likely to differentiate among relationships of varying quality. Along similar lines, because the expectation of both the youth and mentor was to stay together for at least a year, and the duration of each relationship was measured against this benchmark, the tendency to terminate prematurely is likely to be related to the negative aspects of relationships. In much the same way as we would expect marital conflict (as 
opposed to harmony) to predict divorce, acrimony in the mentoring relationship is associated with termination.

The derivation of the youth mentoring inventory contributes in several ways to the growing literature on what contributes to successful mentoring relationships. Consistent with other research (see DuBois et al., 2002; Grossman \& Rhodes, 2002; Slicker \& Palmer, 1993), youth whose bonds with their mentors lasted the longest (13-19 months) reported higher levels of all four factors than did youth whose relationships terminated early (1-6 months). Given that a close, trusting relationship lies at the heart of the change process, this time frame is not surprising. Those programs that recognize the complexity involved, and intentionally support and guide relationships into the longer term, are likely to yield the most promising effects.

Yet, beyond simply staying the course, the actual quality of the relationship is important for bringing about change. Youth who rated the quality of their mentoring relationships more positively had higher levels of two outcome measures, above and beyond the effects of the duration of their relationships. Specifically, youth with higher ratings on the "Trust not broken" subscale reported higher levels of perceived scholastic competence. Youth with higher ratings on "Not dissatisfied" and "Trust not broken" also reported higher levels of global selfworth. It appears that it is not enough simply to meet each week, particularly if there are moments of dissatisfaction and betrayal. Although the proportion of dysfunctional or harmful relationships is relatively low, in part because youth terminate destructive relationships, some relationships may simply be marginallimited in the scope or degree of mentoring functions provided (Ragins, Cotton, $\&$ Miller, 2000). These mentors may mildly disappoint their protégés or may meet only some of their protégés' developmental needs, falling midway on a continuum anchored between highly satisfying and dissatisfying. As D. J. Levinson, Darrow, Klein, M. H. Levinson, and McKee (1978) observed, "Mentoring is not a simple, all-or-none matter" (p. 100), and there must be some degree of trust and closeness for the relationship to be effective.

It is noteworthy that the association between relationship quality and outcome measures extends over the two broad domains of academic achievement and self-esteem. This finding provides further evidence that the positive effects of mentoring can be wide ranging, and can be felt in several different areas of youth's lives (Grossman \& Tierney, 1998). Program administrators using this relationship quality inventory to evaluate the strength of the bonds forming between their volunteers and youth participants can reasonably infer that a young person with poor academic performance or personal self-esteem might experience improvements in these areas if paired with a particularly dedicated, trustworthy, and consistent mentor.

Youth with higher ratings on the "Helped to cope" subscale reported lower levels of global self-worth. There are several ways to interpret this inverse association. It may be the case that such youth were experiencing higher than average stress levels in their lives, which led to (but were not resolved by) mentors' 
increased involvement. Social support researchers have made similar interpretations of positive correlations between social support and distress, i.e., that, rather than causing distress, higher levels of support are mobilized in response to greater difficulty (Vaux, 1988). Whatever led the mentors to provide high levels of coping assistance might also have taken a toll on the youth's sense of well-being. Alternatively, it may be the case that youth who allowed their mentors to help them solve personal problems felt worse about themselves than did those youth who did not let down their guard and solicit the help of an adult. It is also possible, however, that some mentors' solutions to their protégés' problems were not solicited by the youth. Mentors who were focused on improving what they perceived as wrong in their protégés' lives might have undermined protégés' feelings of self-worth. Previous studies of mentoring have also indicated greater success when the mentor follows the lead of the protégé (Morrow \& Styles, 1995). Additional research is needed to determine the circumstances under which these declines in self-esteem occur. Such information could lead to strategies that give rise to mutual trust and respect.

The large, national, longitudinal data set that was analyzed for this research has many unique strengths, but a few of the study's limitations deserve comment. First, the assessments of mentor relationships were based solely on youth's perceptions. Study participants may have been limited in their ability to reflect on the nature of their relationships, or inhibited in their willingness to report personal problems or relationship difficulties. Future studies would do well to supplement adolescent self-report with data from mentors, family members, and case managers, thereby substantially reducing the risk of response bias in the analyses. In particular, a diagnostic tool based at least in part on the observations of case managers or other program staff would be extremely useful. These individuals frequently have access to youth, parents, and mentors, as well as their own valuable perspectives on the quality of the matches they are supervising.

Additional descriptive information regarding the participants might have provided a more nuanced understanding of relationship variation. For example, protégés who had sustained emotional, sexual, or physical abuse are at risk for shorter mentoring relationships (Grossman \& Rhodes, 2002). Maltreated youth might have responded differently than non-maltreated youth to both the questionnaires and the intervention. Children who have suffered maltreatment frequently manifest highly problematic attachment relationship with their parents and others (Carlson, Cicchetti, Barnett, \& Braunwald, 1989) and may find it relatively difficult to establish close, supportive relationships with mentors. Additionally, although not measured, some of the children in this study may have been struggling with learning disabilities that would have affected their academic outcomes.

All of the questionnaires were administered via telephone interviews and, although this approach tends to encourage higher response rates and is less costly than in-person interviews, this strategy may have posed problems. In particular, it omits participants who do not have telephones, it can introduce interviewer 
bias, and it requires a higher level of interviewer training than other approaches (Department of Education, 2003). It should be noted, however, that all of the interviewers were trained in rapport-building and were encouraged to allow participants to adequately reflect on the material.

Additionally, the data that were used in this study are of a retrospective nature, in that adolescents were asked to relate details about their mentoring relationships as they unfolded over the past 18 months. As these data are being used to develop a diagnostic tool that will be used prospectively, to predict relationship quality among mentor-protégé dyads, their retrospective nature is not ideal. The relationship quality inventory that emerged from the present research should be replicated in future studies using non-retrospective data to assess impressions of ongoing relationships.

Finally, although this data set consists of information collected from youth at two time-points 18 months apart, only the second time-point contains data on the nature of the mentoring bond and the youth's perceptions of the mentor. The cross-sectional nature of these data therefore precludes the possibility of assessing the test-retest reliability of the scale. Similarly, data were collected only at the second-time point; scores cannot be seen as "early," but instead reflect youth's impressions after several months of the relationship has elapsed. Although youth in matches of longer duration score significantly more positively on the scale than those in matches of shorter duration, multiple administrations would provide a stronger test of the predictive validity of the mentoring scale.

Despite these limitations, the current research has important implications for both research and practice. The findings underscore previous researchers' assertions that successful mentoring programs must provide continuous support to dyads, and that although longer-lasting matches are associated with positive outcomes, those that terminate prematurely can be harmful (DuBois et al., 2002; Grossman \& Rhodes, 2002; Rhodes, 2002). More generally, there is a need for the continued validation and refinement of this screening instrument. With ongoing refinement, this scale could be used by program evaluators to account for variation in outcome and by program personnel to track relationships over time. Although it is no substitute for adequate infrastructure, an instrument such as this can simplify the work of over-extended mentoring program staff, by helping to identify troubled matches that could be provided with the supervision and attention needed to help them thrive. This might have the effect of reducing the incidence of premature terminations and enhancing the effectiveness of a promising preventive intervention.

\section{ACKNOWLEDGMENTS}

This study was completed with the assistance of a grant from the William T. Grant Foundation. The authors also gratefully acknowledge the assistance of Joseph Tierney and the cooperation of Big Brothers Big Sisters of America. 


\section{REFERENCES}

Albee, G. W. (2000). The Boulder model's fatal flaw. American Psychologist, 55(2), 247-248.

Allen, T. D., \& Poteet, M. L. (1999). Developing effective mentoring relationships: Strategies from the mentor's viewpoint. Career Development Quarterly, 48(1), 59-73.

Anderson, E. (1999). Code of the street: Decency, violence, and the moral life of the inner city. New York: Norton.

Aseltine, R. H., Dupre, M., \& Lamlein, P. (2000). Mentoring as a drug prevention strategy: An evaluation of Across Ages. Adolescent and Family Health, 1(1), 11-20.

Bachelor, A., \& Horvath, A. (1999). The therapeutic relationship. In M. A. Hubble \& B. L. Duncan (Eds.), The heart and soul of change: What works in therapy (pp. 133-178). Washington, DC: American Psychological Association.

Baron, R. M., \& Kenny, D. A. (1986). The moderator-mediator variable distinction in social psychological research: Conceptual, strategic, and statistical considerations. Journal of Personality and Social Psychology, 51, 1173-1182.

Baumrind, D. (1987). A developmental perspective on adolescent risk taking in contemporary America. New Directions in Child Development, 37, 93-125.

Berndt, T., \& Miller, K. (1986). Expectancies, values, and achievement in junior high school. Journal of Educational Psychology, 82, 319-326.

Bollen, K. A. (1989). Structural equations with latent variables. New York: Wiley.

Carson, D. (2002). Mentoring in America 2002: National mentoring poll. Alexandria, VA: National Mentoring Partnership.

Cattell, R. (1966). The scree test for the number of factors. Multivariate Behavioral Research, 1, 245-276.

Davidson, W. S., \& Redner, R. (1998). The prevention of juvenile delinquency: Diversion from the juvenile justice system. In R. H. Price, E. L. Cowen, R. P. Lorion, \& J. Ramos-McKay (Eds.), Fourteen ounces of prevention: Theory, research, and prevention (pp. 123-137). New York: Pergamon.

DuBois, D. L., Holloway, B. E., Valentine, J. C., \& Cooper, H. (2002). Effectiveness of mentoring programs for youth: A meta-analytic review. American Journal of Community Psychology, 30, $157-197$.

Freedman, M. (1993). The kindness of strangers: Adult mentors, urban youth, and the new volunteerism. San Francisco: Jossey-Bass.

Furstenberg, F. (1990). Coming of age in a changing family system. In S. S. Feldman \& G. R. Elliott (Eds.), At the threshold: The developing adolescent (pp.147-170). Cambridge, MA: Harvard University Press.

Gottman, J. (1995). Why marriages succeed or fail: And how you can make yours last. New York: Simon \& Schuster.

Grossman, J. B., \& Johnson, A. W. (1999). Assessing the effectiveness of mentoring programs. In J. B. Grossman (Ed.), Contemporary issues in mentoring (pp. 48-65). Philadelphia: Public/Private Ventures.

Grossman, J. B., \& Rhodes, J. E. (2002). The test of time: Predictors and effects of duration in youth mentoring programs. American Journal of Community Psychology, 30, 199-219.

Grossman, J. B., \& Tierney, J. P. (1998). Does mentoring work? An impact study of the Big Brothers Big Sisters. Evaluation Review, 22, 403-426.

Hair, J. F., Anderson, R. E., Tatham, R. L., \& Black, W. C. (1998). Multivariate data analysis (5th ed.). Upper Saddle River, NJ: Prentice-Hall.

Harter, S. (1986). The self-perception profile for children. Denver, CO: University of Denver, Inventory of School Value.

Herrera, C. L., Sipe, W. S., McClanahan, W. S., Arbreton, A. J., \& Pepper, S. K. (2000). Mentoring school-age children: Relationship development in community-based and school-based programs. Philadelphia: Public/Private Ventures; Arlington, VA: The National Mentoring Partnership.

Jöreskog, K. G., \& Sörbom, D. (2000). Lisrel 8.30 and Prelis 2.30 [computer software]. Linclonwood, IL: Erlbaum.

Kline, R. B. (1998). Principles and practice of structural equation modeling. New York: Guilford. 
Levinson, D. J., Darrow, C. N., Klein, E. B., Levinson, M. H., \& McKee, B. (1978). The seasons of a man's life. New York: Ballantine Books.

LoSciuto, L., Rajala, A. K., Townsend, T. N., \& Taylor, A. S. (1996). An outcome evaluation of Across Ages: An intergenerational mentoring approach to drug prevention. Journal of Adolescent Research, 11(1), 116-129.

Lynch, M., \& Wellborn, J. G. (1987). Relatedness to teachers. In J. G. Wellborn \& J. P. Connell (Eds.), Manual for the Rochester assessment package for schools (pp. 22-48). Rochester, NY: University of Rochester.

McLearn, K. T., Colasanto, D., Schoen, C., \& Shapiro, M. Y. (2000). Mentoring matters: A national survey of adults mentoring young people. In J. B. Grossman (Ed.), Contemporary issues in mentoring (pp. 66-83). Philadelphia: Public/Private Ventures.

McPartland, J. M., \& Nettles, S. M. (1991). Using community adults as advocates or mentors for at-risk middle-school students: A two-year evaluation of Project RAISE. American Journal of Education, 99, 568-586.

Morrow, K. V., \& Styles, M. B. (1995). Building relationships with youth in program settings. Philadelphia: Public/Private Ventures.

Noam, G. (1999). The psychology of belonging: Reformulating adolescent development. In A. H. Esman, L. T. Flaherty, et al. (Eds.), Adolescent psychiatry: Development and clinical Studies, Annals of the American Society for Adolescent Psychiatry, 24 (pp. 49-68). Hillsdale, NJ: Analytic Press.

Ragins, B. R., Cotton, J. L., \& Miller, J. S. (2000). Marginal mentoring: The effects of type of mentor, quality of relationship, and program design on work and career attitudes. Academy of Management Journal, 43(6), 117-119.

Ragins, B. R., \& Scandura, T. A. (1999). Burden or blessing? Expected costs and benefits of being a mentor. Journal of Organizational Behavior, 20(4), 493-509.

Reisner, E., Petry, C., \& Armitage, M. (1998). A review of programs involving college students as tutors or mentors in grades $K-12$. Washington, DC: Policy Studies Associates.

Rhodes, J. E. (2002). Stand by me: The risks and rewards of mentoring today's youth. Cambridge, MA: Harvard University Press.

Rook, K. (1999). For healthy aging, social networks should accentuate the positive. In K. Morris (Ed.), Tip sheet (p. 1). Irvine, CA: University of California.

Sipe, C. L. (1998). Mentoring adolescents: What have we learned. In J. B. Grossman (Ed.), Contemporary issues in mentoring (pp. 24-47). Philadelphia: Public/Private Ventures.

Sipe, C. L., \& Roder, A. E. (1999). Mentoring school-age children: A classification of programs. Philadelphia: Public/Private Ventures.

Slicker, E. K., \& Palmer, D. J. (1993). Mentoring at-risk high school students: Evaluation of a schoolbased program. The School Counselor, 40, 327-334.

Vaux, A. (1988). Social support: Theory, research, and intervention. New York: Praeger. 